\title{
VIRAL-MEDIATED GENE TRANSFER IN THE COCHLEA
}

\author{
MELISSA A. WEISS,* JUAN C. FRISANCHO,* BLAKE J. ROESSLER $\dagger$ and \\ YEHOASH RAPHAEL* $\ddagger$
}

*Kresge Hearing Research Institute, Department of Otolaryngology, The University of Michigan Medical School, MSRB Ill Room 9303; †Department of Internal Medicine, The University of Michigan Medical School, MSRB I Room 5520C, 1150 W. Medical Center Drive, Ann Arbor, MI 48109-0648, U.S.A.

\begin{abstract}
Gene transfer is an exciting new tool in medical therapy and scientific investigation, but only very recently has it begun to be developed in the auditory system. This paper describes in vivo and ex vivo experiments using an adenoviral vector (Ad. RSVntlacZ), which is a replication-deficient virus based on a human adenoviral (serotype 5) genomic backbone. The in vivo experiments demonstrate successful gene transfer into multiple types of cochlear cells. We observed a relatively efficient transduction, several weeks of sustained transgene expression and an absence of major lethal cytotoxicity in spiral ganglion and epithelial cells of the cochlea in adult animals. The ex vivo experiments were performed using fibroblasts transduced in vitro with Ad. RSVntlac $Z$. Two weeks after inoculation of the fibroblasts into the perilymph, we observed transplanted fibroblasts, which were adherent to the lining of the perilymphatic spaces, and were expressing the lac $Z$ transgene. We speculate that, as the genetic basis of degenerative cochlear diseases is characterized on a mutational level, transgene expression will allow us to test hypotheses regarding the effects of specific genes on cochlear cell biology. Gene transfer will not only increase our understanding of the pathophysiology of hearing loss, but also may provide gene therapy for disease. (C) 1997 ISDN
\end{abstract}

Key words: cochlea; adenovirus; gene therapy; guinea pig; adenoviral vectors.

Gene transfer is a powerful technique for altering gene expression in cells and tissues, and the cochlea is potentially a suitable organ for experimental and therapeutic gene transfer. By nature of its structural design, the cochlea possesses several advantages as an end-organ for gene transfer. First, there are several cell types in the cochlea that can be quantified rather precisely. Second, although it is encased in the temporal bone and relatively isolated, inoculation with genetic vectors technically is feasible. Third, the enclosed fluid spaces (the scala tympani and scala vestibuli, which contain perilymph, and the scala media, which contains endolymph) enable diffusible particles, such as viruses or proteins, to disperse rapidly throughout the cochlea. Various agents have been introduced experimentally into the perilymph by injection through the round window membrane, and osmotic pumps have been used to deliver a continuous infusion ${ }^{3}$ into the scala tympani and obtain therapeutic levels of growth factors in the ear. ${ }^{25,26}$

In vivo gene transfer involves inoculation of the target organ with a vector containing a transgenic insert. ${ }^{17}$ In vivo gene transfer in the cochlea achieves transduction of cochlear cells and the transgenic protein produced may exert an effect intracellularly, or if secreted, may diffuse throughout the perilymph and act upon other populations of cochlear cells. In order to introduce genes into any of the quiescent cells of the inner ear (hair cells, supporting cells of the organ of Corti and spiral ganglion cells), in vivo gene transfer is currently the only available technique. In contrast, ex vivo gene transfer typically involves transduction of host cells (such as dermal fibroblasts) in culture, followed by injection of the transduced cells into the cochlea. Ex vivo gene transfer in the cochlea has been demonstrated recently using cultures of neonatal cochlear explants. ${ }^{7}$ Ex vivo gene therapy has two advantages. First, in contrast to in vivo gene transfer in which any cochlear cells potentially may be infected with the virus, ex vivo gene therapy utilizes a preselected host cell population. Second, because a large number of cells may be transduced, a larger dose of transgene potentially may be introduced into the cochlea. The applicability of ex vivo gene therapy is, however, limited to genes that encode diffusible, secreted proteins. 
Achieving efficient cellular transduction and transgene expression is essential for the successful clinical implementation of gene therapy. This efficiency is best achieved using viral vectors, which are more proficient genetic vectors than other available options, such as liposomes or plasmids. Recombinant adenovirus and retrovirus are used frequently as vectors and each has distinctive characteristics that may be advantageous in a particular model. Adenovirus is the vector of choice for many investigators, ${ }^{6,11,12,23}$ and has been used in clinical trials. ${ }^{4,16,29}$ By virtue of its capacity to express its genes in non-dividing cells, adenovirus, unlike retrovirus, is suitable for in vivo gene transfer into the quiescent cells of the cochlea. However, because adenoviral particles do not integrate into the host cell DNA, transgenic expression is relatively short-lived. None the less, in vivo studies have demonstrated expression for as long as 2 months. ${ }^{5,6}$ While the brevity of adenoviral transgene expression may be inadequate for many uses, it may be favorable in others. For example, a potential clinical use of gene therapy in the cochlea is for the transgenic production of growth factors or anti-oxidants to combat ototoxic trauma to the organ of Corti. Furthermore, spiral ganglion cell death typically occurs secondarily after hair cell death. Exposure to therapeutic levels of growth factors for a short time may rescue the spiral ganglion cells, thereby improving the hearing outcome in cochlear implant recipients.

Based on an expanding body of literature regarding the use of recombinant human adenoviruses for in vivo gene transfer, ${ }^{5,6,8,11,12,23,24,29}$ we hypothesized that cochlear cells also would be susceptible to in vivo transduction. We present here data demonstrating (a) the feasibility of transgene expression in cochlear cells in the deafened cochlea using a recombinant adenovirus; and (b) successful ex vivo gene transfer into the cochlea.

\section{EXPERIMENTAL PROCEDURES}

The vector used in our studies (Ad. RSVntlacZ) is a replication-deficient adenovirus based on a human adenoviral (serotype 5) backbone. ${ }^{18,21,22}$ The lac $Z$ gene transcription is driven by the Rous sarcoma virus (RSV) LTR. An SV40 polyadenylation sequence is cloned downstream from the lacZ gene. The $E$. coli $\beta$-galactosidase gene is modified by a nuclear targeting (nt) epitope, so that cells transduced with this vector may be identified by their blue nuclei after incubation in X-gal.

The in vivo experiments were performed using normal ${ }^{21}$ as well as deafened guinea pigs. To deafen the animals, we injected kanamycin ( $400 \mathrm{mg} / \mathrm{kg} \mathrm{s.c.)}$ and ethacrynic acid $(40 \mathrm{mg} / \mathrm{kg}$ i.v.) as described previously. ${ }^{13,28,30}$ Two guinea pigs, deafened 2 weeks previously with kanamycin and ethacrynic acid, ${ }^{28,30}$ were given prophylactic chloramphenicol $(30 \mathrm{mg} / \mathrm{kg} \mathrm{SC})$, and anesthetized with xylazine $(10 \mathrm{mg} / \mathrm{kg}$ s.c. $)$ and ketamine $(40 \mathrm{mg} / \mathrm{kg}$ s.c.). The left round window was approached through a post-auricular incision, the bulla was exposed and sharply punctured with the scalpel. The opening was enlarged with curved forceps and the round window identified. Each guinea pig was inoculated with $5-10 \mu$ l of an isotonic adenoviral suspension $\left(10^{11}\right.$ adenoviral particles $/ \mathrm{ml}$ sterile PBS), injected through the round window membrane using a Hamilton syringe. A fascial graft was placed over the round window membrane, Durelon carboxylat-cement (ESPE) was applied to the bony defect, and the soft tissue was closed in two layers. The right cochlea served as a negative control for each animal. Seven days after viral inoculation, the animals were anesthetized with chloral hydrate $(0.1 \mathrm{cc} / 100 \mathrm{~g}$ i.p. $)$ and perfused transcardially with fresh $4 \%$ paraformaldehyde. The tissues were incubated overnight in X-gal, and post-fixed with $2 \%$ glutaraldehyde. The distribution of lacZ+ cells within the cochlea was assessed stereoscopically. Cochleae then were decalcified in EDTA with $1 \%$ glutaraldehyde and prepared for sectioning (either cryo or plastic).

To assess the extent of inflammatory response, we used antibodies to detect $\mathrm{T}$ cells. Three guinea pigs were inoculated with the adenoviral vector described above $\left(10^{11}\right.$ adenoviral particles $\left./ \mathrm{ml}\right)$, sacrificed 1 week later, fixed in 4\% PFA, reacted with guinea pig $T$ lymphocytes-specific antibody (MCA 564, Serotec, U.K.). We used the peroxidase DAB reaction with a Vectastain kit (Vector Labs) as chromogen and assessed the tissue with a stereoscope.

For the ex vivo experiments, guinea pig fibroblasts (kindly provided by Dr Thomas Carey, Kresge Hearing Research Institute) were maintained in culture with minimal essential media under standard culture conditions, and the same viral vector, Ad. RSVntlac $Z$, was used for the viral transductions. Fibroblasts were grown to near-confluence in six-well tissue culture plates, rinsed once with PBS 
and then incubated with Ad. RSVntlac $Z$ with a multiplicity of infection (MOI) of $10^{5}$ in $1 \mathrm{ml}$ aliquots of minimal essential media at $37^{\circ} \mathrm{C}$. After $2 \mathrm{hr}$, an additional $1 \mathrm{ml}$ of minimal essential media with $10 \%$ fetal calf serum was added to each well. At the time of surgery, the fibroblasts were harvested by trypsinization and $10^{4}$ cells were resuspended in 10-20 $\mu$ l of sterile PBS. Two guinea pigs, deafened 2 weeks previously with kanamycin and ethacrynic acid, ${ }^{28,30}$ were given prophylactic chloramphenicol $(30 \mathrm{mg} / \mathrm{kg}$ s.c.), and anesthetized with xylazine and ketamine. The left round window was exposed surgically, and the cells very slowly injected through the round window membrane using a Hamilton syringe. The wound was closed as described above. The right cochlea served as a negative control for each animal.

Post-operatively, the animals recovered without head-tilt, circling behavior or signs of systemic toxicity. After 1 week, the animals were anesthetized with chloral hydrate $(0.1 \mathrm{cc} / 100 \mathrm{~g}$ i.p. $)$ and fixed transcardially with fresh $4 \%$ paraformaldehyde. The temporal bones were isolated, the apex of the bony cochlea opened and the cochlea directly infused with fixative. To visualize lacZ in transduced cells, cochleae were developed in X-gal. For T cell immunocytochemistry, the tissues were permeabilized with $0.3 \%$ Triton X-100 and double-labeled with monoclonal antibody specific for guinea pig T lymphocytes (Serotec, U.K.). Antibody binding sites were visualized with biotinilated anti-mouse antibodies and peroxidase DAB reaction using the Vectastain kit (Vector Labs), turning the positive cells brown.

\section{RESULTS}

The extent of in vivo viral transduction in deafened animals appears larger than that previously reported in normal animals. ${ }^{21}$ Large numbers of blue nuclei were seen throughout these cochleae [Fig. 1(A)-(C)]. The T cell immunocytochemistry revealed results similar to those observed previously in normal cochleae transduced with adenovirus. More specifically, there was a modest increase in the number of $T$ cells present, primarily in the lining of the perilymphatic fluids (data not shown).

The perilymph of cochleae inoculated with transduced fibroblasts was clear and without signs of a major inflammatory response. Stereoscopic examination of inoculated cochleae demonstrated what appeared to be a nearly confluent layer of blue nuclei lining the osseous spiral lamina of the basal turn of the cochlea, and a few blue cells in the second and third turns [Fig. 1(D)]. The contralateral (control) ears did not exhibit any lac $Z+$ cells, and the vestibular tissue of the experimental ears was also negative after development with $X$-gal. The $T$ cell immunocytochemistry (data not shown) demonstrated a moderate immune response, similar in magnitude to the in vivo experiments. The $\mathrm{T}$ cell distribution was fairly uniform throughout the cochlea, with the exception of the basal tum, which had virtually no inflammatory cells. Light micrograph sections demonstrated multiple blue nuclei, as well as negative nuclei, in a thickened layer of connective tissue, lining the osseous spiral lamina. Both gross and histologic sections in all of the experimental cochlea demonstrated changes typically found after of pharmacological deafening, but otherwise preserved architecture of the cochlea.

\section{DISCUSSION}

We have reported previously detailed results of in vivo gene transfer in normal guinea pigs. ${ }^{21}$ To summarize briefly, a large number of cells with blue nuclei were observed throughout experimental cochleae, and transduced cell types included supporting cells in the organ of Corti, several cell types in the stria vascularis, spiral ligament cells, fibrocytes in the perilymphatic scalae and spiral ganglion cells. Transduced cells could be detected 3 weeks after the inoculation. Hair cells were not transduced with this virus. The efficiency of infection varied among animals and among cell types within an animal; spiral ganglion cell transduction was particularly efficient in some animals, and not in others. The $\mathrm{T}$ cells were observed near the fibrocytes lining the perilymphatic spaces and were present in greater numbers in experimental cochleae than in controls. Plastic sections of experimental ears did not reveal signs of major toxicity in the organ of Corti or the spiral ganglion regions.

The deafened cochleae transduced in vivo and presented in this paper [Fig. 1(A)-(C)], demonstrate 


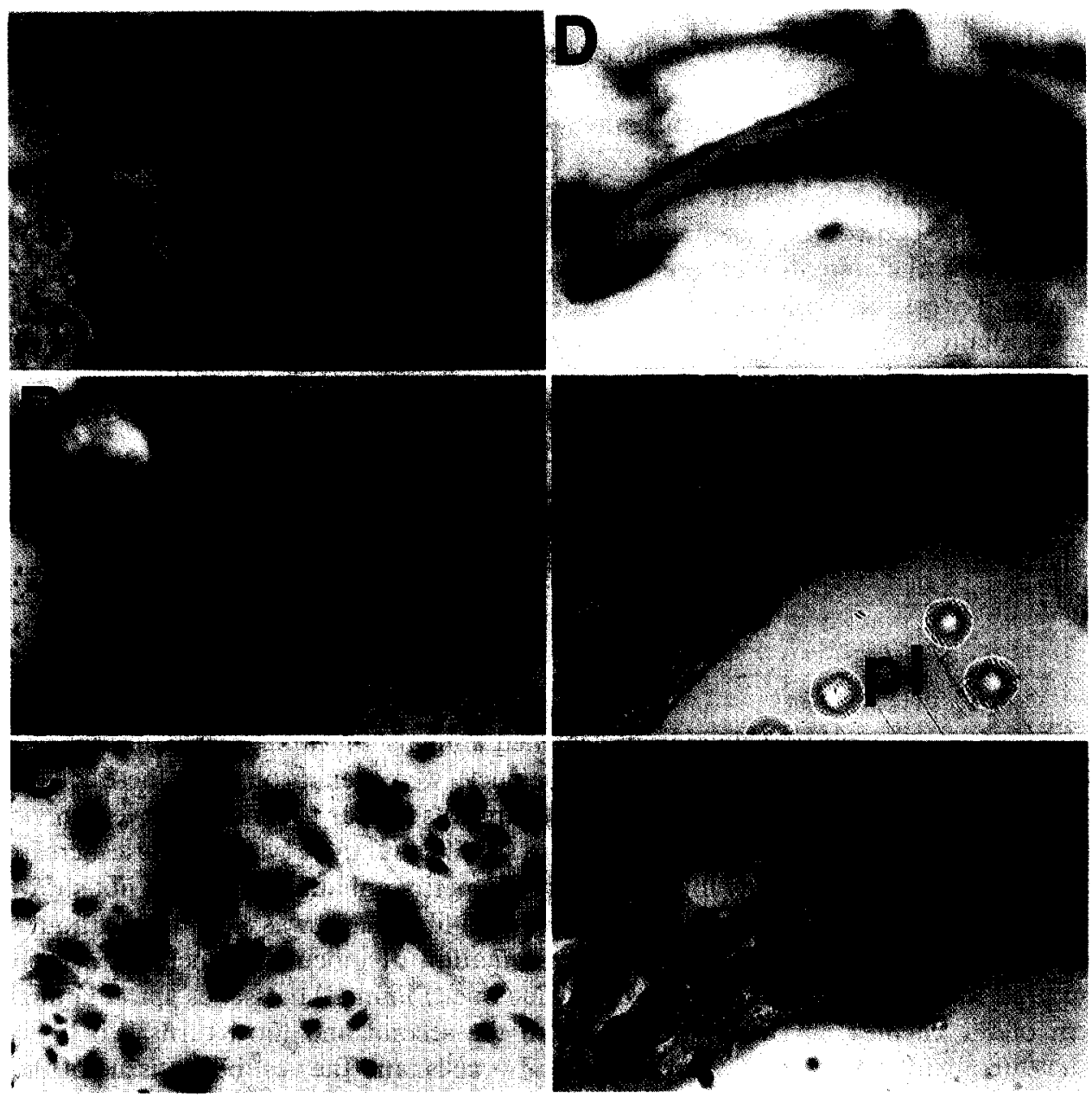

Fig. 1. Guinea pig cochleae of animals transfected with lacZ adenovirus and developed with X-gal, demonstrating transduced cells with blue nuclei. (A)-(C) Show cochleae from deafened animals transfected in vivo; (D)-(F) are from animals transfected ex vivo. (A) Stereoscopic micrograph of a cochlea which was inoculated with the adenovirus (on the right) exhibits blue nuclei, evenly distributed throughout the cochlear turns. The contralateral cochlea (on the left) is the non-inoculated control. (B) Under higher magnification, numerous blue nuclei are seen in the scala vestibuli (sv) and the scala tympani (st). (C) A whole-mount of Reissner's membrane from the third cochlear tum, demonstrating multiple blue nuclei. (D) Stereoscopic view of the basal turn (scala tympani side) of a cochlea transfected ex vivo. Cells with blue nuclei occupy the region near the osseous spiral lamina. (E) and (F) Plastic sections (at a near midmodiolar plane) demonstrate the osseous spiral lamina (arrow) and a thickened layer of connective tissue, with multiple blue nuclei, lining the perilymphatic space (pl). A higher magnification view of this area $(\mathrm{F})$ shows a few lac $Z$ negative (purple) among the lac $Z$ positive (blue) nuclei.

a greater extent of genetic transduction than was observed previously after transduction of normal cochleae. ${ }^{21}$

These data, as well as those previously reported ${ }^{21}$ demonstrate that in vivo gene transfer achieves efficient gene delivery into the cochlear tissues. However, in vivo transduction of the inner ear has two potential problems associated with it that we attempted to circumvent with ex vivo transduction. First is the difficulty of controlling expression of the transgene. In vivo gene transfer does not allow selection of the type or number of cells infected by the virus, or the quantity of gene product produced. Ex vivo transduction requires that the target cells be selected, sustained in cell culture, genetically transduced, and then transplanted into the host animal. This process allows for selection of the host cell, determination of the MOI and episomal copy number and, after transduction, 
quantification of transgenic protein expression. All of this may be done prior to transplantation of the cells into the cochlea.

The second potential problem with in vivo adenoviral gene transfer is the inflammatory response that typically is associated with an active adenoviral infection. ${ }^{27} E x$ vivo transduction with a replication-deficient virus does not expose the animal directly to the viral particles, and theoretically may limit the inflammatory stimulus. In addition, adenovirus is an efficient vector for ex vivo gene transfer, achieving high episomal copy numbers per target cell.

Although interpretation of the data on ex vivo transduction presented in this paper is limited by the small number of experimental animals, our preliminary results demonstrate that cultured fibroblasts can be transduced and that transgenic expression persists for at least 1 week in the cochlea. In addition, the non-injected control (right) cochleae demonstrated neither blue nuclei nor blue cytoplasmic staining, indicating that, with the technique used here, viral infection remains specific to the experimental organ. Moreover, no major changes were observed in the morphology of the organ of Corti, stria vascularis or spiral ganglion cells in Rosenthal's canal, suggesting that adenovirus infection was not associated with direct lethal cytotoxicity to any of the epithelial or neural cochlear cells (data not shown).

While no major toxicity was observed, the magnitude of $T$ cell infiltration was comparable between in vivo and ex vivo gene transfer. Our hypothesis that the latter approach may be less immunogenic requires further study. Objectives of our current investigations are to elucidate the components of the inflammatory stimulus through a series of negative controls and sham operations. In addition, we are doing longitudinal studies to determine the temporal limits of cell survival and transgene expression.

These results are consistent with other animal models demonstrating that parenteral administration of recombinant adenovirus to specific organ systems elicits an initial cell-mediated immune response. ${ }^{6,18}$ However, the magnitude of the host $\mathrm{T}$ cell response to the intra-cochlear administration of recombinant adenovirus is limited. We believe that the absence of a massive immune response in our experiments is related to the unique anatomic properties of the cochlea and the fact that the administration procedure through the round window does not appear to compromise extensively the integrity of the blood-perilymph barrier. The preservation of the normal anatomic isolation of the cochlear cells from direct contact with mononuclear cells may provide for tolerable levels of immune-mediated toxicity after a single intra-cochlear dose with recombinant adenovirus.

The data presented here, in conjunction with previously reported results, ${ }^{21}$ demonstrate the transduction of a variety of cochlear cell types using in vivo gene transfer, as well as the plausibility of ex vivo gene transfer, all without eliciting a major inflammatory or cytotoxic response. Together they strongly suggest that the cochlea is an adequate target organ for developing gene transfer technology for experimental and clinical purposes.

The utility of adenovirus as a vector for transgene expression in other systems has been tempered by its potential to cause local or systemic toxicity. While recombinant adenoviral vectors have been shown to be effective in mediating gene transfer in the mammalian nervous system with a relatively low risk of toxicity, ${ }^{6}$ both infectious and non-infectious particles are capable of eliciting an inflammatory response. ${ }^{2,4}$

Other potential viral vectors include herpes virus, adeno-associated virus, and retrovirus. Herpes virus is peculiar in its natural preference for infecting neurons, making it possible to direct gene therapy to this specific cell population. However, herpes virus is associated with considerable cytotoxicity, which remains an obstacle in its clinical use. ${ }^{9,10}$ Second generation herpes virus vectors with reduced toxicity currently are being developed. Adeno-associated viruses, which have minimal toxicity, have been used successfully as vectors for gene transfer and may have an expanded role in the future..$^{14,17}$ Retroviruses may be considered for ex vivo gene transfer in the cochlea; however, their efficiency of transduction and levels of transgene expression are much lower than those achieved with adenovirus. ${ }^{1,19,20}$ As our understanding of the viral regulation of gene expression deepens, we may learn to prolong the duration of gene expression, minimize toxicity of infection, and increase the specificity of infection, which would broaden the potential applicability of this very powerful tool. $^{15}$

In summary, gene transfer is an exciting new technology with both experimental and potentially therapeutic utility in the cochlea. The data reviewed and presented here demonstrate successful gene 
transfer in the cochlea. We hypothesize that, as the molecular basis for degenerative cochlear diseases becomes better understood, transgene expression will not only allow us to test the impact of specific genes in the cochlea, but also may open the door to repairing cochlear pathology.

Acknowledgements-We would like to thank Lynnell Fritsma and Jackie Kaufman for their help with tissue dissection, processing, sectioning, and photography. This work was supported in part by the National Organization for Hearing Research (NOHR), NIDCD Program Project \# DC00274, and NIH Training Grant \# DC00024.

\section{REFERENCES}

1. Bannerji R. (1995) In Viral Vectors: Gene Therapy and Neuroscience Applications (eds Kaplitt M. G. and Loewy A. D.), pp. 75-88. Academic press, San Diego, CA.

2. Brody S. L. and Crystal R. G. (1994) Adenovirus-mediated in vivo gene transfer. Ann. NY Acad. Sci. 716, 90-101.

3. Brown J. N., Miller J. M., Altschuler R. A. and Nuttall A. L. (1993) Osmotic pump implant for chronic infusion of drugs into the inner ear. Hearing Res. 70, 167-172.

4. Crystal R. G., McElvaney N. G., Rosenfeld M. A., Chu C. S., Mastrangeli A., Hay J. G., Brody S. L., Jaffe H. A., Eissa N. T. and Danel C. (1994) Administration of an adenovirus containing the human CFTR cDNA to the respiratory tract of individuals with cystic fibrosis. Nat. Genet. 8, 42-51.

5. Davidson B. L., Allen E. D., Kozarsky K. F., Wilson J. M. and Roessler B. J. (1993) A model system for in vivo gene transfer into the central nervous system using an adenoviral vector. Nat. Genet. 3, 219-223.

6. Davidson B. L., Doran S. E., Shewach D. S., Latta J. M., Hartman J. W. and Roessler B. J. (1994) Expression of Escherichia coli beta-galactosidase and rat HPRT in the CNS of Macaca mulatta following adenoviral-mediated gene transfer. Expl Neurol. 125, 258-267.

7. Dazert S., Battaglia A. and Ryan A. F. (1997) Transfection of neonatal rat cochlear cells in vitro with an adenovirus vector. Intl J. Dev. Neurosci. 15, 595-600.

8. Doran S. E., Roessler B. J., Hartman J. W., Hoff J. T., Shewach D. S. and Davidson B. L. (1994) Adenovirus-mediated in vivo gene transfer into the central nervous system of a nonhuman primate (resident award paper). Clin. Neurosurg. 41, 242-257.

9. Fink D. J., Steinberg L. R., Weber P. C., Mata M., Goins W. F. and Glorioso J. C. (1992) In vivo expression of betagalactosidase in hippocampal neurons by HSV-mediated gene transfer. Hum. Gene Ther. 3, 11-19.

10. Glorioso J. C., Coins W. F., Meaney C. A., Fink D. J. and DeLuca N. A. (1994) Gene transfer to brain using herpes simplex virus vectors. Ann. Neurol. 35 Suppl, S28-34.

11. Guzman R. J., Lemarchand P., Crystal R. G., Epstein S. E. and Finkel T. (1993) Efficient and selective adenovirusmediated gene transfer into vascular neointima. Circulation 88, 2838-2848.

12. Jaffe H. A., Danel C., Longenecker G., Metzger M., Setoguchi Y. and Rosenfeld M. A. (1992) Adenovirus-mediated in vivo gene transfer and expression in normal rat liver. Nat. Genet. 1, 372-378.

13. Jyung R. W., Miller J. M. and Cannon S. C. (1989) Evaluation of eighth nerve integrity by the electrically evoked middle latency response. Otolaryngol. Head Neck Surg. 101, 670-682.

14. Kaplitt M. G., Leone P., Samulski R. J., Xiao X., Pfaff D. W., O’Malley K. L. and During M. J. (1994) Long-term gene expression and phenotypic correction using adeno-associated virus vectors in the mammalian brain. Nat. Genet. 8, 148154.

15. Kaplitt M. G. and Loewy A. D. (eds) (1995) Viral Vectors: Gene Therapy and Neuroscience Applications. Academic Press, San Diego, CA.

16. Korst R. J., Bewig B. and Crystal R. G. (1995) In vitro and in vivo transfer and expression of human surfactant SP-Aand SP-B-associated protein cDNAs mediated by replication-deficient, recombinant adenoviral vectors. Hum. Gene Ther. 6, 277-287.

17. Lalwani A. K., Walsh B. J., Reilly P. G., Muzyczka N. and Mhatre A. N. (1996) Development of in vivo gene therapy for hearing disorders: introduction of adeno-associated virus into the cochlea of the guinea pig. Gene Ther. 3, 588-592.

18. Le Gal La Salle G., Robert J. J., Berrard S., Ridoux V., Stratford-Perricaudet L. D., Perricaudet M. and Mallet J. (1993) An adenovirus vector for gene transfer into neurons and glia in the brain. Science 259, 988-990.

19. McCoy R. D., Davidson B. L., Roessler B. J., Huffnagle G. B. and Simon R. H. (1995) Expression of human interleukin1 receptor antagonist in mouse lungs using a recombinant adenovirus: effects on vector-induced inflammation. Gene Ther. 2, 437-444.

20. Miller D. G. and Miller A. D. (1993) Inhibitors of retrovirus infection are secreted by several hamster cell lines and are also present in hamster sera. J. Virol. 67, 5346-5352.

21. Raphael Y., Frisancho J. C. and Roessler B. J. (1996) Adenoviral-mediated gene transfer into guinea pig cochlear cells in vivo. Neurosci. Lett. 207, 137-141.

22. Roessler B. J., Hartman J. W., Vallace K. D., Latta J. M., Janich S. L. and Davidson B. L. (1995) Inhibition of interleukin-1-induced effects in synoviocytes transduced with the human IL-1 receptor antagonist cDNA using an adenoviral vector. Hum. Gene Ther. 6, 307-316.

23. Rosenfeld M. A., Siegfried W., Yoshimura K., Yoneyama K., Fukayama M., Stier L. E., Paakko P. K., Gilardi P., Stratford-Perricaudet L. D., Perricaudet M., Jallet S., Pavirani A., Lecocq J.-P. and Crystal R. G. (1991) Adenovirusmediated transfer of a recombinant alpha 1-antitrypsin gene to the lung epithelium in vivo. Science 252, 431-434.

24. Rosenfeld M. A., Yoshimura K., Trapnell B. C., Yoneyama K., Rosenthai E. R., Dalemans W., Fukayama M., Bargon J., Stier L. E., Stratford-Perricaudet L., Perricaudet M., Guggino W. B., Pavirani A., Lecocq J.-P. and Crystal R. G. (1992) In vivo transfer of the human cystic fibrosis transmembrane conductance regulator gene to the airway epithelium. Cell 68, 143-155.

25. Schindler R. A., Gladstone H. B., Scott N., Hradek G. T., Williams H. and Shah S. B. (1995) Enhanced preservation of the auditory nerve following cochlear perfusion with nerve growth factors. Am. J. Otol. 16, 304-309.

26. Shah S. B., Gladstone H. B., Williams H., Hradek G. T. and Schindler R. A. (1995) An extended study: protective effects of nerve growth factor in neomycin-induced auditory neural degeneration. Am. J. Otol. 16, 310-314. 
27. Shenk T. (1995) In Viral Vectors: Gene Therapy and Neuroscience Applications (eds Kaplitt M. G. and Loewy A. D.), pp. 43-53. Academic Press, San Diego, CA.

28. Webster M. and Webster D. B. (1981) Spiral ganglion neuron loss following organ of Corti loss: a quantitative study. Brain Res. 212, 17-30.

29. Welsh M. J., Smith A. E., Zabner J., Rich D. P., Graham S. M., Gregory R. J., Pratt B. M. and Moscicki R. A. (1994) Cystic fibrosis gene therapy using an adenovirus vector: in vivo safety and efficacy in nasal epithelium. Hum. Gene Ther. $5,209-219$.

30. West B. A., Brummett R. E. and Himes D. L. (1973) Interaction of kanamycin and ethacrynic acid. Severe cochlear damage in guinea pigs. Arch. Otolaryngol. 98, 32-37. 